\title{
Recommendation and physical activity practice in Brazilians with chronic diseases
}

\author{
Paulo Sergio Cardoso da Silva1* (1), Tiago Rodrigues de Lima² (i), \\ Lúcio José Botelho ${ }^{1}$ (D), Antonio Fernando Boing ${ }^{1}$
}

\begin{abstract}
SUMMARY
OBJECTIVE: To analyze the prevalence and factors associated with professional recommendation and leisure-time physical activity (LTPA) in Brazilian individuals diagnosed with hypertension (HBP), diabetes, and/or hypercholesterolemia.

METHODS: This is a cross-sectional population-based study with a representative sample of the Brazilian population (aged $\geq 20$ years) in 2013, with self-reported HBP ( $n=11.098)$, diabetes $(n=3.176)$, and/or hypercholesterolemia $(n=7.252)$. Prevalence and gross odds ratios were estimated and adjusted for both outcomes.

RESULTS: Professional recommendation and LTPA were more prevalent in individuals who received recommendation and presented with hypercholesterolemia ( 85.9 and $23.4 \%$, respectively). Adjusted analysis showed an association in people 40 to 59 years of age and public programs in most diseases. Higher educational level was associated with receiving recommendations in all non-communicable diseases (NCDs). LTPA was associated in people 40 to 59 years of age for HBP and diabetes and in all investigated NCDs, higher educational level, positive perception of health, and a favorable environment in those who received recommendation.

CONCLUSIONS: Education presented the greatest magnitude in the associations, clearly showing the need for equitable methods to increase recommendation and LTPA levels for the most vulnerable population. Further studies analyzing other variables and NCD are needed, corroborating the Ministry of Health.

KEYWORDS: Physical activity. Adherence, patient. Chronic disease. Non-communicable. Health surveys. Health personnel.
\end{abstract}

\section{INTRODUCTION}

Non-communicable diseases (NCDs) are responsible for 41 million deaths in the world ${ }^{1}$ annually. In Brazil, approximately $45 \%$ of the adult population presents at least one $\mathrm{NCD}^{2}$. The main risk factors for NCDs are smoking, excessive consumption of alcoholic beverages, poor food quality, overweight, and insufficient physical activity on prescription (PAP) $)^{1,3}$. PAP accounts for the annual costs for health systems worldwide, which is estimated to exceed $\$ 50$ billion ${ }^{4}$. Conversely, sufficient PAP has a positive effect on the prevention of health-related diseases, in addition to contributing to control and prevention of early mortality attributed to $\mathrm{NCDs}^{5}$.

Environmental, demographic, socioeconomic, and psychocognitive factors $^{6}$ are PAP conditioning factors. In addition, the literature indicates the important role of health professionals and services in stimulating PAP. Some studies show that the recommendation of physical activity by health professionals to service users ${ }^{7}$, especially by physicians $s^{8,9}$, is associated with behavioral changes and an increase in $\mathrm{PAP}^{7,10}$. However, few

1Universidade Federal de Santa Catarina, Departamento de Saúde Pública, Programa de Pós-Graduação em Saúde Coletiva - Florianópolis (SC), Brazil. Universidade Federal de Santa Catarina, Departamento de Educação Física, Programa de Pós-Graduação em Educação Física - Florianópolis (SC), Brazil. *Corresponding author: pauloscs85@gmail.com

Conflicts of interest: the authors declare there is no conflicts of interest. Funding: none.

Received on September 02, 2020. Accepted on September 29, 2020. 
studies have investigated this association in Brazil ${ }^{7,8,11}$, especially in Brazilian individuals with NCDs.

Investigating the knowledge on PAP recommendation by health professionals in individuals with a NCD is particularly important in middle-income countries, such as Brazil, which have high social and individual costs attributed to NCDs and scarce resources to deal with such health conditions ${ }^{2,4,12}$. Moreover, Brazil has the goal of increasing the prevalence of leisure-time PAP (LPAP) and decreasing the growth of obesity among Brazilian adults, according to the Strategic Action Plan for $\mathrm{NCDs}^{3}$.

This study aimed to analyze the prevalence and factors associated with professional recommendation and LPAP in Brazilian individuals diagnosed with HBP, diabetes, and/or hypercholesterolemia.

\section{METHODS}

This is a cross-sectional study based on microdata from the 2013 National Health Plan (PNS) conducted by the Brazilian Institute of Geography and Statistics (IBGE). This study has a domiciliary characteristic, national representativeness, and a population base with three-stage sampling by conglomerates. The questionnaire was completed by 60,202 adults $^{13}$.

This study included adults aged $\geq 20$ years who self-reported HBP, diabetes, and/or hypercholesterolemia. To identify the pathological condition, they were asked: "Has any doctor ever diagnosed you with [pathology]?" with the option of answering "yes" or "no."

The professional recommendation for physical activity variable was also self-referred (yes, no), and the enough leisure-time physical activity variable considered sufficiently active participants those who performed at least $150 \mathrm{~min} /$ week of light or moderate PAP or at least $75 \mathrm{~min} /$ week of vigorous PAP at leisure time, or a combination of moderate and vigorous activities totaling $150 \mathrm{~min}$ a week ${ }^{5}$. The classification of the activity intensity was based on weekly frequency, duration, and intensity ${ }^{14,15}$.

The exploratory variables were sex (male or female); self-reported race/skin color (black, brown, white); age group (2039, 40-59, $\geq 60$ years); marital status (married, separated/ divorced/widowed, single); education (no education, incomplete/complete elementary school, incomplete/complete high school); self-perception of health status (positive, good and very good; negative, other answers); self-reported presence of public space near the household for PAP (yes, no); and self-reported presence of public programs that stimulate PAP (yes, no) in the city.
The analyses described the prevalence of the outcomes and their $95 \%$ confidence intervals $(95 \% \mathrm{CI})$ by exploratory variables. Subsequently, logistic regression was performed, and gross odds ratio (OR) values were estimated and adjusted with the respective 95\%CI. The Stata 12.0 software was used, considering individual sample weights and complex sampling.

\section{RESULTS}

The study sample consisted of individuals with hypercholesterolemia $(n=7,252)$, diabetes $(n=3,176)$, and hypercholesterolemia $(n=11,098)$, and its distribution included more women and individuals aged $\geq 40$ years, were whites and brown were married, had completed elementary school education, had negative health perception, and reported no space for PAP or public programs that stimulate PAP. The prevalence of both professional PAP and LPAP in those who received recommendation were higher in individuals with hypercholesterolemia (85.9 and $23.4 \%$, respectively). In all NCDs, the two outcomes investigated were less prevalent in older individuals, who had a lower educational level and negative health perception (except for recommendations to individuals with diabetes), and to those who declared to have no space and PAP public programs (Table 1).

An adjusted analysis showed distinct associations among different investigated NCDs. Individuals with HBP aged 40-59 years had a $27 \%$ higher chance of receiving a recommendation than older individuals. Public space and public programs were also associated with PAP. In individuals with diabetes, those aged $40-59$ years who were white had 105 and $60 \%$ higher chances of receiving a recommendation, respectively, compared to older and black individuals. Married individuals with hypercholesterolemia had a $46 \%$ higher chance of receiving a recommendation compared to separated/divorced/widowed individuals. For all investigated NCDs, an educational level of high school or college was positively associated with receiving a recommendation (Table 2).

Among those who received a PAP recommendation, an adjusted analysis in all NCDs showed that a positive self-perception of health, the presence of space and PAP public programs, and a high educational level were positively associated with adequate LPAP. A high educational level increased the chances of LPAP 2.5 times in individuals with HBP, 2.1 times in those with diabetes, and 3.1 in those with hypercholesterolemia compared to individuals with a low educational level (Table 3). 


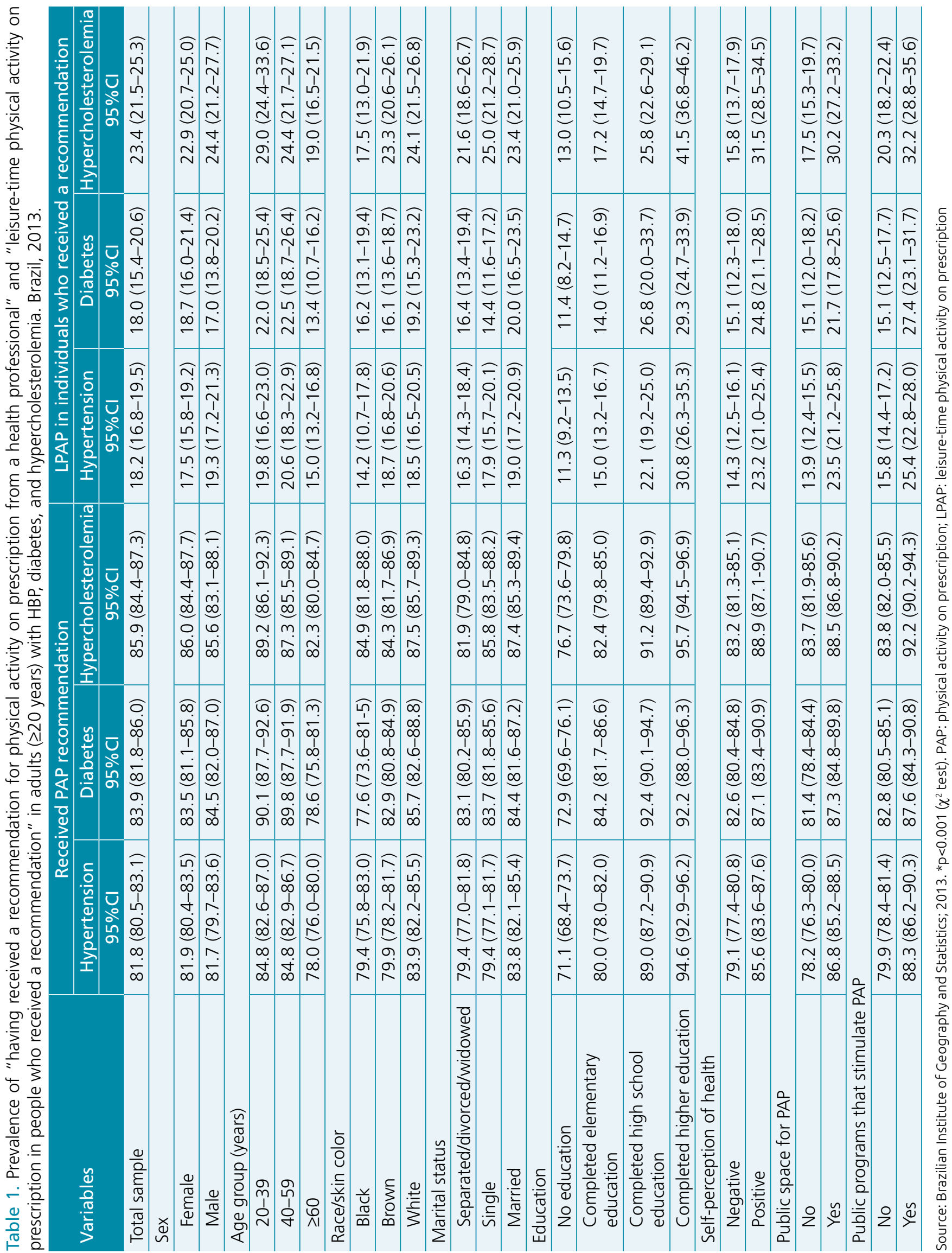




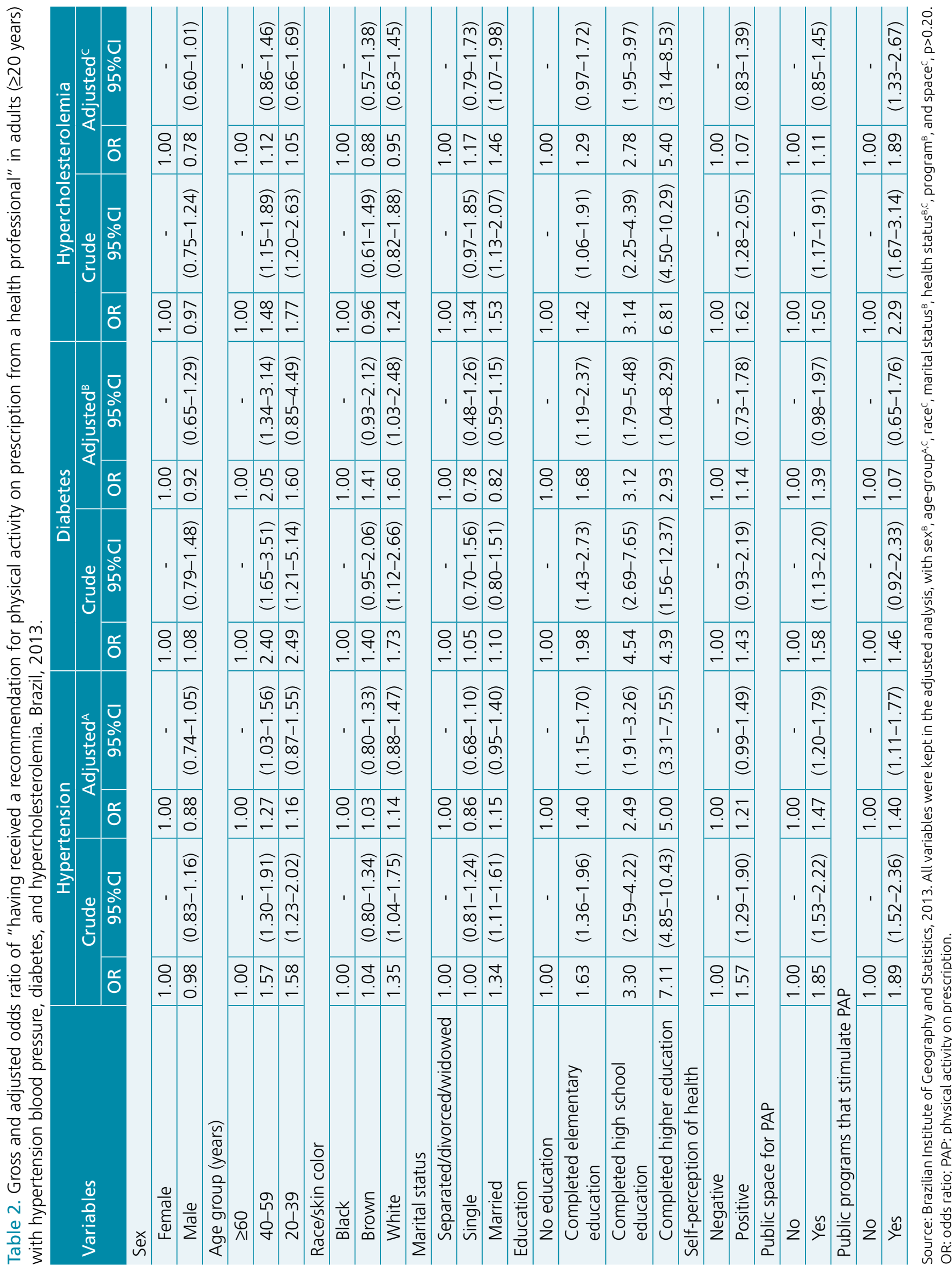




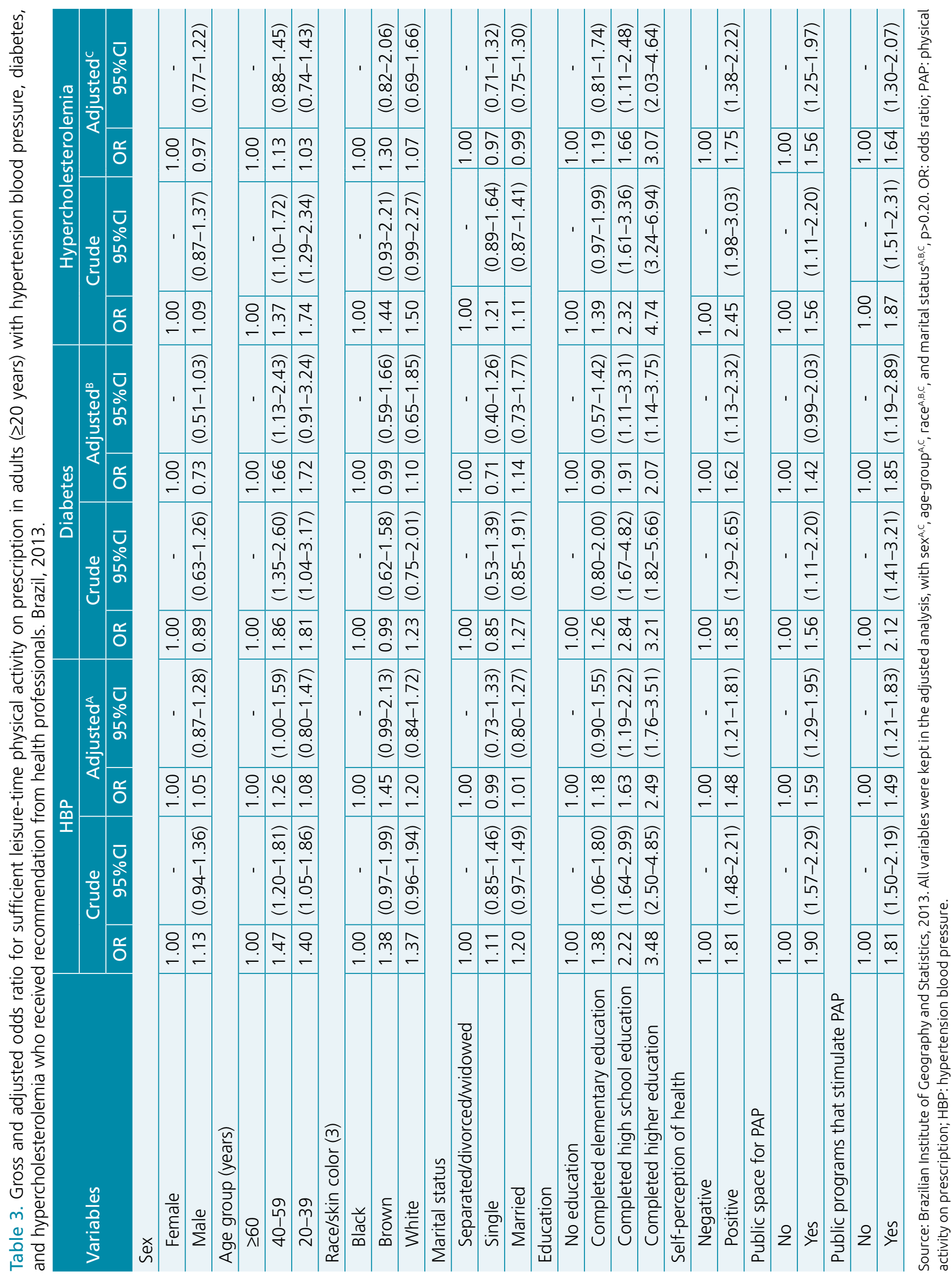




\section{DISCUSSION}

The results showed that receiving a PAP recommendation was positively associated with the age group 40-59 years (except for hypercholesterolemia), with being white (in individuals with diabetes), with being married (in individuals with hypercholesterolemia), and with having space (in individuals with HBP) and public PAP programs (except for individuals with diabetes). Educational level was the only variable associated with the outcome in all NCDs. In those who received a recommendation, LPAP presented positive association with higher educational level, positive self-perception of health, and presence of space and public PAP programs in all NCDs.

In Brazil, approximately $59.3 \%$ of individuals received some recommendation for adopting a healthy behavior in primary care ${ }^{9}$. One of the associated factors is the presence of an $\mathrm{NCD}^{8,11,16}$, justifying the high prevalence of recommendations. Corroborating the results of this study, other studies also reported higher prevalence of both PAP recommendation ${ }^{11,16}$ and sufficient LPAP ${ }^{10,14,15,17}$ in married individuals, with a higher educational level, and access to public spaces and programs.

As for the age group, there was a higher prevalence of recommendations for older adults and younger elderly individuals ${ }^{16}$. The demand for health services and professional recommendation is highly prevalent in elderly individuals ${ }^{7}$ but, with advancing age, NCD and physical limitations may hinder PAP, reducing recommendations for older individuals who cannot perform them. LPAP was more prevalent among adults, which may be justified by better health status and lower limitations resulting from NCD in this group ${ }^{13}$. Although there was a higher prevalence of recommendations and PAP in individuals with positive health perception, only PAP showed an association in an adjusted analysis, corroborating a study investigating the same $\mathrm{NCD}^{17}$. Positive health perception presupposes greater susceptibility to adhere to LPAP $^{6}$, which may justify the association.

As in other studies, the favorable environment for PAP was associated with receiving recommendations ${ }^{11}$ and LPAP ${ }^{10,17,18}$. Places such as health units, gym centers, and green spaces in the area increase recommendations and LPAP ${ }^{11}$, possibly because the health professional considers that the user would be able to comply with the recommendations. Decision making for PAP considers the effects of space and context ${ }^{19}$, highlighting a person's sense of safety, urbanization, geography, and climate ${ }^{6,18}$. Some studies highlight the importance of environments built to address PAP inequalities. Although wealthier individuals have more knowledge on the existing public programs, individuals with lower income participate more often in these program $\mathrm{s}^{20}$. Adequate spaces for PAP close to the household are associated with higher $\mathrm{PAP}^{18}$; therefore, public health promotion policies can help fight inequalities when aimed at the most vulnerable regions.

Having a higher educational level increased the chances of both outcomes. Studies identified the same bias for recommendation ${ }^{11}$ and LPAP ${ }^{10,14,15,17}$. The lower occurrence of recommendation for individuals with a lower educational level replicates a perverse logic, in which those who need it most have less access or use a service of lower quality. Similar behavior was found in patients with high cardiovascular risk, where those with lower income had less access to diagnostic health services ${ }^{21}$. Considering the positive relationship between education and income ${ }^{22}$, higher education provides individuals with objective conditions to meet the recommendations. Professional recommendation is a way to promote health and, according to the principle of equity, greater attention to the most vulnerable population is expected. They need more social support, objective conditions, and motivation for behavioral changes ${ }^{23}$. Another hypothesis for the results obtained would be the greater engagement of individuals with higher educational level for LPAP since they were more knowledgeable ${ }^{15}$.

One limitation of this study is its cross-sectional design, which makes it impossible to infer causality, and self-reported NCD leads to a memory bias of the participants. Considering that the presence of NCD is associated with an increased use of health services, a possible selection bias cannot be excluded, especially because individuals with undiagnosed disease are not included in the analyzed sample.

\section{CONCLUSIONS}

Being in the 40-59 years of age group and having a higher educational level, a positive perception of health, and the existence of public spaces and PAP programs were associated with both receiving professional PAP recommendation and being more leisure-time physically active in individuals who received professional recommendation.

Educational level was the variable associated with the greatest magnitude, pointing to the need for strategies capable of attenuating the evident inequalities found to increase LPAP recommendation in the most vulnerable population.

\section{AUTHORS" CONTRIBUTIONS}

PSCS: Conceptualization, Data curation, Formal analysis, Investigation, Methodology, Writing - original draft, Writing review \& editing. TRL: Conceptualization, Data curation, Writing - review \& editing. LJB: Conceptualization, Writing review \& editing. AFB: Conceptualization, Formal analysis, Methodology, Validation, Writing - review \& editing. 


\section{REFERENCES}

1. World Health Organization. Time to deliver: report of the WHO independente high-level commission on noncommunicable diseases. Geneva: World Health Organization; 2018.

2. Malta DC, Bernal RTI, Souza MFM, Szwarcwald CL, Lima MG, Barros MBA. Social inequalities in the prevalence of self-reported chronic non-communicable diseases in Brazil: national health survey 2013. Int J Equity Health. 2016;15(1):153. https://doi.org/10.1186/s12939-0160427-4

3. Malta DC, Oliveira TP, Santos MAS, Andrade SSCA, Silva MMA. Avanços do plano de ações estratégicas para o enfrentamento das doenças crônicas não transmissíveis no Brasil, 2011-2015. Epidemiol Serv Saúde. 2016;25(2):373-90. https://doi.org/10.5123/S1679-49742016000200016

4. Ding $D$, Lawson KD, Kolbe-Alexander TL, Finkelstein EA, Katzmarzyk PT, van Mechelen W, et al. The economic burden of physical inactivity: a global analysis of major non-communicable diseases. Lancet. 2016;388(10051):1311-24. https://doi. org/10.1016/S0140-6736(16)30383-X

5. World Health Organization. Global recommendations on physical activity for health. Geneva: World Health Organization; 2010. [cited On Jun 22, 2019]. Available from: http:// whqlibdoc.who.int/publications/2010/9789241599979_eng. pdf?ua $=1$

6. Dumith SC. Proposal of a theoretical model to physical activity adoption. Rev Bras Ativ Fís Saúde 2008;13(2):110-20.

7. Flores TR, Gomes AP, Soares ALG, Nunes BP, Assunção MCF, Gonçalves $\mathrm{H}$, et al. Aconselhamento por profissionais de saúde e comportamentos saudáveis entre idosos: estudo de base populacional em Pelotas, sul do Brasil, 2014. Epidemiol Serv Saúde. 2018;27(1):e201720112. https://doi.org/10.5123/ S1679-49742018000100012

8. Häfele $V$, Siqueira FV. Aconselhamento para atividade física e mudança de comportamento em Unidades Básicas de Saúde. Rev Bras Ativ Fís Saúde. 2016;21(6):581-92. https:// doi.org/10.12820

9. Santos RP, Horda PM, Sousa CS, Santos CA, Oliveira HBS, Almeida LMR, et al. Aconselhamento sobre alimentação e atividade física: prática e adesão de usuários da atenção primária. Rev Gaúcha Enferm. 2012;33(4):14-21. https://doi. org/10.1590/S1983-14472012000400002

10. Peixoto SV, Mambrini JVM, Firmo JOA, Loyola Filho Al, Souza Junior PRB, Andrade FB, et al. Prática de atividade física entre adultos mais velhos: resultados do ELSI-Brasil. Rev Saúde Pública. 2018;52(Suppl 2):5s. https://doi.org/10.11606/ S1518-8787.2018052000605

11. Lopes ACS, Toledo MTT, Câmara AMCS, Menzel HJK, Santos LC. Condições de saúde e aconselhamento sobre alimentação e atividade física na atenção primária à saúde de Belo Horizonte-MG. Epidemiol Serv Saúde. 2014;23(3):305-16.
12. Malta DC, Stopa SR, Szwarcwald CL, Gomes NL, Silva Júnior $J B$, Reis AAC. A vigilância e o monitoramento das principais doenças crônicas não transmissíveis no Brasil - Pesquisa Nacional de Saúde, 2013. Rev Bras Epidemiol. 2015;18(supl. 2):3-16. https://doi.org/10.1590/1980-5497201500060002

13. Instituto Brasileiro de Geografia e Estatística. Pesquisa Nacional de Saúde: 2013: percepção do estado de saúde, estilos de vida e doenças crônicas. Brasil, grandes regiões e unidades da federação. Rio de Janeiro: Instituto Brasileiro de Geografia e Estatística; 2014.

14. Cruz MS, Bernal RTI, Claro RM. Tendência da prática de atividade física no lazer entre adultos no Brasil (2006-2016). Cad Saúde Pública. 2018;34(10):e00114817. https://doi. org/10.1590/0102-311X00114817

15. Camelo LV, Figueiredo RC, Oliveira-Campos M, Giatti L, Barreto SM. Comportamentos saudáveis e escolaridade no Brasil: tendência temporal de 2008 a 2013. Ciênc Saúde Colet. 2016;21(4):101121. https://doi.org/10.1590/1413-81232015214.09742015

16. Siqueira FV, Nahas MV, Facchini LA, Silveira DS, Piccini RX, Tomasi $\mathrm{E}$, et al. Aconselhamento para a prática de atividade física como estratégia de educação à saúde. Cad Saúde Pública. 2009;25(1):203-13.

17. Forechi L, Mill JG, Griep RH, Santos I, Pitanga F, Molina MDCB. Adherence to physical activity in adults with chronic diseases: ELSA-Brasil. Rev Saude Publica 2018;52:31. https:// doi.org/10.11606/S1518-8787.2018052000215

18. Florindo AA, Barrozo LV, Cabral-Miranda W, Rodrigues EQ, Turrell G, Goldbaum M, et al. Public open spaces and leisuretime walking in brazilian adults. Int J Environ Res Public Health. 2017;14(6):553. https://doi.org/10.3390/ijerph14060553

19. Loch MR, Dias DF, Castro ASR, Guerra PH. Controle remoto ou remoto controle? A economia comportamental e a promoção de comportamentos saudáveis. Rev Panam Salud Publica. 2019;43:e18. https://doi.org/10.26633/RPSP.2019.18

20. Ferreira RW, Caputo EL, Häfele CA, Jerônimo JS, Florindo AA, Knuth AG, et al. Acesso aos programas públicos de atividade física no Brasil: Pesquisa Nacional de Saúde, 2013. Cad Saúde Pública 2019;35(2):e00008618. https://doi.org/10.1590/0102$311 \times 00008618$

21. Campbell DJT, Ronksley PE, Manns BJ, Tonelli M, Sanmartin $C$, Weaver RG, et al. The association of income with health behavior change and disease monitoring among patients with chronic disease. PLoS One. 2014;9(4):e94007. https:// doi.org/10.1371/journal.pone.0094007

22. Kawachi I, Adler NE, Dow WH. Money, schooling, and health: mechanisms and causal evidence. Ann NY Acad Sci. 2010;1186:5668. https://doi.org/10.1111/j.1749-6632.2009.05340.x

23. Pampel FC, Krueger PM, Dennery JT. Socioeconomic disparities in health behaviors. Annu Rev Sociol. 2010;36:349-70. https:// doi.org/10.1146/annurev.soc.012809.102529 